IZA DP No. 8289

Do Employers Prefer Undocumented Workers?

Evidence from China's Hukou System

Peter Kuhn

Kailing Shen

June 2014 


\title{
Do Employers Prefer Undocumented Workers? Evidence from China's Hukou System
}

\author{
Peter Kuhn \\ University of California, Santa Barbara, \\ NBER and IZA \\ Kailing Shen \\ WISE, Xiamen University \\ and IZA
}

Discussion Paper No. 8289

June 2014

IZA

P.O. Box 7240

53072 Bonn

Germany

Phone: +49-228-3894-0

Fax: +49-228-3894-180

E-mail: iza@iza.org

Any opinions expressed here are those of the author(s) and not those of IZA. Research published in this series may include views on policy, but the institute itself takes no institutional policy positions. The IZA research network is committed to the IZA Guiding Principles of Research Integrity.

The Institute for the Study of Labor (IZA) in Bonn is a local and virtual international research center and a place of communication between science, politics and business. IZA is an independent nonprofit organization supported by Deutsche Post Foundation. The center is associated with the University of Bonn and offers a stimulating research environment through its international network, workshops and conferences, data service, project support, research visits and doctoral program. IZA engages in (i) original and internationally competitive research in all fields of labor economics, (ii) development of policy concepts, and (iii) dissemination of research results and concepts to the interested public.

IZA Discussion Papers often represent preliminary work and are circulated to encourage discussion. Citation of such a paper should account for its provisional character. A revised version may be available directly from the author. 


\section{ABSTRACT \\ Do Employers Prefer Undocumented Workers? Evidence from China's Hukou System}

We study urban Chinese employers' preferences between workers with and without a local residence permit (hukou) using callback information from an Internet job board serving private sector employers. We find that employers prefer migrant workers to locals who are identically matched to the job's requirements; these preferences are especially strong at low skill levels. We argue that migrants' higher work hours and effort help to account for employers' preferences, and present evidence that efficiency wage and intertemporal labor substitution effects might explain these hours/effort gaps.

JEL Classification: $\quad$ O15, R23

Keywords: $\quad$ temporary migration, China, hukou, undocumented migrants

Corresponding author:

Peter Kuhn

Department of Economics

University of California, Santa Barbara

Santa Barbara, CA 93106

USA

E-mail: pjkuhn@econ.ucsb.edu

\footnotetext{
This research is supported by National Natural Science Foundation of China through Grant No. 71203188, titled "Impacts of Hukou, Education and Wage on Job Search and Match: Evidence Based on Online Job Board Microdata". Both authors contributed equally to the research in this paper.
} 
"I'd rather hire a foreigner - they push themselves more... The mentality is just different. Those who come from overseas have this huge drive to succeed. When you come here, your family expects you to succeed no matter what. You can't come here, the land of opportunity, and fail. They'll think you're crazy." -- Ola Ayeni, founder of startup Eateria, reported on CNNMoney, February 7, 2013.

\section{Introduction}

A common claim in popular discussions of immigration is that employers prefer to hire workers with limited residency rights -such as those on temporary visas and undocumented entrants - over equally qualified natives, because these migrant workers are willing to work harder, for longer hours, and for less pay. Perhaps surprisingly, this claim has apparently not been directly assessed in the vast empirical literature on immigration, whether in the U.S. or in other countries. One reason, of course, is that workers with limited or nonexistent documents and the firms employing them may have incentives to hide their status from investigators. Another reason is the scarcity of firmlevel data on immigrants, especially data on applicant pools with information on visa status.

Studying how workers with limited residency rights fare in the hiring process does more than address a common claim in public discourse. It also provides useful evidence on the causes of immigrant-native gaps in employment and wages more generally, and contributes specifically to our understanding of the economics of temporary migration-- an growing and important aspect of migration that has been relatively overlooked. As Dustmann (2000) has pointed out, the incentives facing temporary migrants differ substantially from those facing permanent migrants, favoring large responses on hours and effort margins among the former, versus investment in hostregion-specific skills in the latter. Since the legal status of the migrant workers we study strongly discourages them from forming permanent ties with the host economy, they represent a group whose ex ante intentions to stay in the host region are likely very low; such groups can be hard to identify empirically but shed useful light on the temporary migration process.

Specifically, this paper studies employers' choices between workers with and without permanent residency rights in an important but understudied context: China's cities. As is well known, China's cities have experienced massive in-migration over the past several decades. Indeed, in some large cities migrants constitute a majority of the employed population. A unique and less well known feature of this migration is that unlike the U.S., and unlike many other developing nations, Chinese people do not have the right to permanently reside in any part of the country. Instead, each person is born with a city or province of permanent registration (hukou). While this does not prevent people from migrating to other jurisdictions for temporary work, it places severe limits on their ability to settle permanently in any location other than the one corresponding to their birth hukou. Since a worker's hukou status is relatively public information, China's 
internal migration system provides a unique laboratory in which to study employers' preferences between workers with different residency rights.

To that end, this paper uses internal data from the main Internet job board of Xiamen, a medium-sized, prosperous Chinese city about the size of Los Angeles, to pose the following question: Among equally qualified local hukou (LH) versus non-local hukou (NLH) candidates who have applied for the same job, which applicants are more likely to receive an employer contact? Our main finding is that employers on this job board, which caters to private-sector firms, prefer workers without a permanent residence permit over equally-matched permanent residents; specifically there is a robust difference in callback rates of about 1.4 percentage points, or 20 percent. While possible explanations of this gap include within-job wage discrimination against migrants, positive selection of migrants, and higher work effort among migrants, we argue that it is hard to explain the patterns in the data without at least some role for the latter factor. To our knowledge, ours is the only paper to study employers' hiring choices between workers with and without permanent residency rights in any jurisdiction. ${ }^{1}$

Section 2 provides some background on China's hukou system, both nationally and as it applies to our study city. Section 3 describes our data and methods while Section 4 presents the main results. Section 5 discusses possible causes for employers' NLH preference in our data, while Section 6 concludes.

\section{What is Hukou?}

\subsection{Hukou in China}

Hukou is the legal right to permanently reside in a province or city. It is inherited from a parent (historically the mother) regardless of where one is born, and is very difficult to change. For example, neither long periods of residence in a new location, or marriage to a person of different hukou are sufficient to change one's hukou. The institution of hukou is ancient, dating back to Shang dynasty (1617 BC - 1046 BC), and was originally used by local rulers to prevent emigration. More recently, under China's planned economy, hukou was extensively used by the central government to restrict internal migration, while nowadays it is primarily migrant-receiving provinces' and cities' hukou-based policies that constrain migrants' rights. While Chinese workers are de facto relatively free to migrate and take jobs in areas where they do not have a permanent residence permit, both state and city governments have created a set of rules that distinguish between local hukou (LH) and non-local hukou persons (NLH) in a number of key markets, including those for housing, labor, education and health. Local governments

\footnotetext{
${ }^{1}$ Borjas and Tienda (1993), Rivera-Batiz (1999), Kossoudji and Cobb-Clark (2002) and Barcellos (2010) study the effect on workers of acquiring legal status in the U.S. While they generally find that workers' labor market outcomes improve as a result of legalization, they do not address the question of which type of workers employers prefer to hire, holding qualifications fixed. Oreopoulos (2011) studies Canadian employers' choices between natives and persons with Asian-sounding names, but the latter are predominantly legal permanent residents.
} 
also set the rules for how migrants can acquire a local hukou. ${ }^{2}$ Since China is, to our knowledge, the only major country where residency rights are allocated by sub-national governments, it provides a unique opportunity for the study of migration and migration policy.

One main set of legal differences between LH and NLH persons in most Chinese jurisdictions is in eligibility for government-provided benefits and services. For example, access to public primary education (9 years) is generally guaranteed only to persons with local hukou; NLH children are sometimes accommodated if space is available, but availability can be highly limited in the major migrant-receiving cities. ${ }^{3}$ And since most social insurance programs, including public retirement benefits, medical insurance, unemployment insurance, industrial injury insurance and childbirth benefits are all administered by China's provincial and city governments, migrants are treated differently by these programs as well. Typically, this involves both lower benefits and lower payroll taxes. Also, despite recent attempts to improve access and portability, some benefits that have been earned can be hard to access. For example, it can be difficult to claim retirement benefits earned in a city after leaving it.

The second main set of legal distinctions between NLH and LH persons is a patchwork of rules limiting migrants' access to certain labor and real estate markets. Hukou-based restrictions apply in many urban housing markets, including long waiting periods before a non-local is allowed to buy a home. ${ }^{4}$ In addition, a variety of formal and informal restrictions affect the types of jobs NLH workers are allowed to take. While often hard to document officially, a variety of sources report explicit or implicit bans in Beijing on hiring NLH persons as taxi drivers, hotel front desk personnel, lawyers, and in Kentucky Fried Chicken stores. Some state-owned enterprises, as well as provincial and city governments, are claimed to favor LH workers, and occasionally will even announce explicit LH quotas. ${ }^{5}$ These and other features of China's hukou system continue to

\footnotetext{
${ }^{2}$ The main pathways for acquiring hukou in a new location are through family relationships, business investment, and targeted labor recruitment, though in all cases the barriers are steep. Waiting periods for family cases can be as long as 15 years. Local governments sometimes make small numbers of local hukous available to businesses in exchange for major investments, and sometimes offer expedited access to designated categories of 'highly skilled' individuals, state-owned enterprise (SOE) employees, and local government employees.

${ }^{3}$ Access to public high schools is usually very limited for NLH children, though exceptions are made for 'highly desired talents'. That said, even NLH children who gain access to urban primary schools often choose to return home for high school, in order to prepare for college admission exams which must be taken in the official hukou location. .

${ }^{4}$ In Beijing and Shanghai, for example, non-local hukou holders must be in the local social insurance and payroll tax system for a pre-specified period of time before being allowed to buy a home. Similar restrictions apply to entering the lottery for a car license plate. In at least some cities, eligibility for public and subsidized housing is restricted to LH persons only.

${ }^{5}$ See Huang (2010) regarding lawyers and Aimeiaishenghu (2013) regarding taxi drivers. Hukou-based requirements for hotel front desk personnel and KFC employment have been claimed by a number of commentators on social media. Aluminum Corporation of China (2012) is an ad for new college and university graduates placed by a large SOE. The company advertises an explicit recruitment quota of 30 percent $\mathrm{LH}$ and 70 percent NLH, but adds the following note at the bottom of the ad: "Note: Beijing students, education can be relaxed".
} 
evolve rapidly. For a more detailed discussion of the institution's history and ongoing evolution, see Chan and Buckingham (2008), Bao, Bodvarsson, Hou and Zhao (2009), or Démurger and $\mathrm{Xu}$ (2013).

The LH and NLH populations of China's major cities are described in Table 1, which is calculated from 2005 Census microdata. Column 1 (LH) shows characteristics of all working-age persons who have a permanent residence permit in their current city of residence. Column (2) (NLH) is for the remainder of urban residents, whose hukou registration is elsewhere; most but not all of these persons are rural-urban migrants from poorer parts of China. In the following discussion we also refer to LH and NLH persons as natives and migrants, respectively.

A first observation from Table 1 is that NLH workers form a large share of the population of China's major cities: $51 \%$ of these cities' residents, and $57 \%$ of their employed residents do not have a local hukou. In addition, migrants are much younger than natives, and have much less education: 48 percent of migrants are 35 or younger, compared to 30 percent of natives. Sixty-four percent of migrants have at most a junior middle school education (9 years) compared to 38 percent of natives. Several statistics in Table 1 show a much higher level of labor force commitment among migrants than natives. For example, 77 percent of working-age migrants are employed, compared to 62 percent of urban natives. Seventy-six percent of migrants' income comes from the labor market, compared to 61 percent for working-age urban LH persons. Among persons who work, migrants put in an average of 49.14 hours per week, compared to 44.10 for urban natives. Finally, 57 percent of NLH workers worked more than 40 hours per week, compared to just 30 percent of natives.

Reflecting the differential treatment by the social insurance system discussed above, Table 1 also shows that many fewer migrants are eligible for social insurance coverage. This difference occurs despite their higher levels of labor force commitment -which under a uniform policy would qualify more of them for benefits-- and applies separately to unemployment insurance, medical insurance and public pension coverage. Reflecting both this lower eligibility and their higher rates of labor force participation, only 6 percent of working-age migrants' income was from public transfers, compared to 23 percent of working-age natives'. Unsurprisingly, employed migrants also have less formal work arrangements. Only $(33+15=) 48$ percent have any form of employment contract, compared to 74 percent of natives, and the duration of their contracts is much shorter. Finally, consistent with the notion that NLH workers face barriers to public sector employment, only 22 percent of employed migrants work in the public sector or in SOEs, compared to 62 percent of employed urban natives. As we shall argue, this strong tendency for urban natives to cluster in non-private-sector jobs provides an important context for our results in this paper, which as already noted apply to private-sector jobs only 


\subsection{Hukou in Xiamen}

During the period of our data (July 2010 to June 2011), LH and NLH workers in our study city, Xiamen, paid the same mandatory payroll taxes for unemployment insurance, worker's compensation, and childbirth benefits, and were entitled to the same benefits under these programs. The two most important social insurance programsretirement and medical insurance - however, provided much lower benefits to NLH workers, but also levied lower payroll taxes on those workers. Since these tax and benefit differences could affect employers' preferences between LH and NLH workers, we detail their structure in Section 5 of the paper. Both NLH and LH children enjoy free tuition in Xiamen's elementary and junior middle schools, but LH children have priority in admissions: any places not filled by LH children are assigned by lottery among NLH children. In practice this can severely restrict access to NLH children. ${ }^{6}$ NLH persons' access to housing markets is also restricted in Xiamen, mainly by the fact that persons without local hukou may currently purchase a maximum of one apartment; this constitutes an important difference between locals and migrants because real estate investments are reportedly a significant income source for many local residents. Routes for NLH workers to acquire Xiamen hukou are similar to other major migrant receiving areas, though certainly less restrictive than the 'hottest' migration destinations, including Beijing, Shanghai and Guangzhou (BeiShangGuang).

Descriptive statistics on Xiamen's LH and NLH populations are provided in columns 3 and 4 of Table 1, which replicate columns 1 and 2 for the city of Xiamen only. As in other major cities, Xiamen's NLH population is younger, less well educated, more likely to be employed, yet less likely to have social insurance coverage than its workingage native population. When employed, migrants work much longer hours ( 74 percent put in more than 57 hours per week) and have less formal and permanent employment arrangements. Xiamen has an even larger NLH population share than other major cities, constituting 56 percent of its residents and 61 percent of its workers.

With 21 and 23 percent of its LH population employed in public sector jobs and SOEs respectively, Xiamen's native workers are actually less concentrated in the broader public sector than in other major cities (where the comparable numbers are 21 and 41 percent). Still, as in other cities, Xiamen's NLH workers are dramatically underrepresented in public- and quasi-public sector jobs; only 4 percent of them have public sector jobs and 11 percent work in SOEs. While we are aware of no formal restrictions excluding NLH workers from public sector jobs in Xiamen, this gap suggests that some hiring preferences, similar to those documented in Beijing, might exist in Xiamen also.

\footnotetext{
${ }^{6}$ For example, Xiamen News Net (2013) documents an August 27, 2013 protest where several hundred NLH parents blocked the entrance road to a Xiamen primary school, demanding access for their children. In part because NLH students can only take college entrance exams in their home provinces, and since the materials, the admission process, and admission rates vary across provinces, NLH students typically do not attend high school in Xiamen.
} 
In sum, in Xiamen as in most major migrant-receiving cities in China, the hukou system is relatively accommodating to unattached persons who wish to work in the city for a limited period of time; in fact it even includes NLH workers - at reduced tax and benefit rates-- in its social insurance system. At the same time, Xiamen limits migrants' access to some key public benefits - especially education and retirement benefits - in ways that can make it hard for NLH workers to put down roots and raise a family. Xiamen also appears to make it hard for NLH workers to get jobs in the broader public sector (government plus SOEs). While Xiamen is perceived as being somewhat more welcoming to NLH workers than larger destination cities like Beijing and Shanghai, official policy goals of the local government still appear to place different weights on the welfare of native and migrant workers. Specifically, local labor market policy objectives tend to emphasize protection of LH workers, such as reducing unemployment and assisting displaced workers, while objectives involving NLH workers emphasize their role as a source of labor supply to allow industrial growth. ${ }^{7}$ Naturally, one would expect these policy differences to affect both the type of worker who migrates to Xiamen as an NLH worker, and those workers' labor market behavior after they arrive. We explore these differences in the remainder of the paper.

\section{Data and Methods}

\subsection{Xiamen and XMRC}

The city of Xiamen had a 2010 Census population of 3.5 million, and forms the center of a prosperous metropolitan area of 16.8 million people on China's southern coast. In part because Xiamen was one of the five economic zones established immediately after the 1979 economic reforms that opened China to the international economy, the city is highly modernized and integrated into the world economy relative to most similarlysized Chinese cities. While considerably smaller in population than Beijing and Shanghai, Xiamen's income levels are relatively close to those cities', with 2010 GDP per capita at 58,337 RMB, compared to 75,943 and 76,074 RMB for Beijing and Shanghai respectively.

XMRC (http://www.Xmrc.com.cn), the job board that is the source of our data, is a for-profit company sponsored by the local government. While its primary mandate is to serve the market for skilled, private-sector workers in the Xiamen metropolitan area, in fact it serves private-sector employers seeking workers with a wide range of skills. XMRC operates like a typical U.S. job board, with both job ads and resumes posted online. Workers and firms can contact each other to submit applications, arrange interviews, etc., through the site. ${ }^{8}$

\footnotetext{
${ }^{7}$ For example, a 2007 statement on "Improving Employment and Re-employment" includes the following targets, specifically for LH workers: an unemployment rate of under 4 percent, and a re-employment rates for displaced and 'hard-to-employ' LH workers of at least $60 \%$. Goals involving NLH workers in the same statement mostly focus on increasing the total numbers employed.

${ }^{8}$ The other main employment service in the Xiamen area is XMZYJS (the Xia-Zhang-Quan 3 city public job board, www.xmzyjs.com), that is operated directly by local government employees of the local labor
} 
Our analysis sample is extracted from XMRC's internal database. Specifically, we asked XMRC to provide us with all the ads for jobs in Xiamen that received their first application between May 1 and October 30, 2010. Then we asked XMRC to provide us with all the resumes that applied to those ads, plus information on all the firms that posted those ads. We also have a mapping of which resumes applied to which ads, and a record of which resumes were contacted by each firm through the XMRC website. Receiving such a contact is our indicator of worker success in the hiring process. ${ }^{9}$ To ensure that we capture all contacts resulting from applications made during our sampling window, we continued to monitor all the ads posted during that window until January 13, 2011 (74 days after Oct. 30 2010). Most contacts occur very quickly, however (within 2 weeks of application). Finally, since our interest is in which workers are selected by firms for interviews or employment, the sample of ads used in this paper restricts attention to ads that resulted in at least one worker being contacted by the firm. ${ }^{10}$

Other criteria used in constructing our analysis sample include excluding ads with a minimum requested age below 18 or a maximum requested age over 60; ads offering more than 10,000 yuan/month; ads requesting a master's, professional or $\mathrm{PhD}$ degree (all of these were rare); ads for more than 10 vacancies (since job descriptions tended to be vague), ads for jobs located outside the city of Xiamen, and ads with missing firm information. We also dropped resumes listing a current wage above 12,500 yuan/month, with missing hukou information, or with non-Chinese citizenship, as well as applications that couldn't be matched to both an ad and a resume. Finally, we dropped a small number of XMRC ads for jobs in State-Owned Enterprises and Not-for-Profit organizations. Despite being a substantial share of employment in Xiamen, ads for SOE jobs are very rare on XMRC, as most recruiting for these positions goes through other channels. Thus our results refer to hiring for private-sector jobs only.

\subsection{Sample characteristics}

In all, our data consist of 237,128 applications that were made by 82,113 workers (resumes) to 3,708 ads placed by 1,653 firms. Sample means are presented in Table 2, separately for workers with local and non-local hukou. A first, important fact from Table 2 is that the XMRC site is populated primarily with ads from workers without Xiamen hukou; in fact about 91.9 percent of the applications are from workers without local hukou. This preponderance of NLH workers, while at first glance surprising, is less so

bureau. Its mandate is to serve less-skilled workers; reflecting this, XMZYJS does not post worker resumes and does not allow firms and workers to contact each other via the site. Indeed, a large component of the services provided by XMZYJS is brick-and-mortar offices where workers can go to view job postings and meet with employers.

${ }^{9}$ Since only about 8 percent of applications in our sample result in such contacts, we interpret these contacts as a relatively strong interest on the firm's part in hiring the worker. Conversations with XMRC officials support this interpretation, as does evidence in all our regressions (detailed below) that the probability of contact is strongly and positively related to the quality of the match between workers' characteristics and the job's advertised requirements.

${ }^{10}$ No responses could mean the firm didn't hire during our observation period, or they contacted successful workers using means other than the job board. 
when we recall that 61 percent of Xiamen's employed population does not have local hukou, and that posting a resume on an Internet job board such as XMRC would be a natural port of entry into Xiamen's labor market for workers from outside the city. Indeed, the fact that many of the NLH applicants on XMRC could be applying from a distance makes our result that firms seem to prefer NLH applicants even more surprising. ${ }^{11}$

Overall, Table 2 shows that 7.1 percent of applicants with local hukou are contacted by firms' HR departments when they apply for a job. This figure rises to 8.5 percent among applicants without local hukou. Put a different way, in the raw data, NLH workers have a $20 \%$ greater chance of receiving a callback when they apply for a job. Users of XMRC are highly qualified, even by urban Chinese standards. Focusing first on the NLH workers, the mean applicant has 14.4 years of education and a mean wage in his/her current job (among the $69 \%$ of applicants who list a current wage) of 2263 yuan per month. These workers are applying to jobs with a mean minimum education requirement of 12.5 years, and with a mean advertised wage of 2372 yuan (for ads where the wage is advertised). Our sample of applicants is also very young, with a mean age under 25 years; this reflects the tendency for both jobseekers and internet users to be younger than the average worker. Nineteen percent are new graduates. On average, when the number of positions available was specified, about 2.1 positions were available per ad.

While most of the differences between LH and NLH workers in Table 2 are statistically significant due to the large sample sizes, in the vast majority of cases the differences are quantitatively very small, and exhibit few clear patterns. One substantial difference, however, is that NLH workers are younger and more likely to be new graduates, which is perhaps not surprising since the early career may be the time when workers seek to relocate to a new city.

Part (b) of Table 2 illustrates the detailed list of applicant characteristics that are measured in our data. Among these characteristics are several that are rare in other data sets, including the applicant's current wage, height, an indicator for myopia, the number of schools attended, experience spells, and professional certifications. In addition, a unique feature of our data is that we observe each applicant's level of qualification within his/her occupation, or zhicheng. Zhicheng is a nationally-recognized system that assigns an official rank (from one through six) to workers in almost every occupation. While education and experience play key roles in many occupations' ranking schemes, several professions also use government-organized nationwide or province-wide exams both to qualify for and to maintain one's zhicheng rank. ${ }^{12}$

\footnotetext{
${ }^{11}$ Unfortunately, our confidentiality agreement with XMRC does not allow us to determine where applicants are living when they apply to jobs via the website.

12 In addition to providing a summary index of workers' skills, workers' zhicheng ranks can also confer direct benefits to the firm. For example, construction firms are required to have certain minimum number of construction managers above a certain zhicheng rank to be permitted to do projects of a given type.
} 
Comparing Tables 1 and 2, our sample of applicants on XMRC differs from the employed population of Xiamen in at least two important ways. One, already noted, is that despite being a substantial share of jobs in the city, public sector and SOE jobs are so rarely posted on XMRC that we excluded them from our analysis sample. Second, applicants on XMRC are much younger and better educated than Xiamen's employed labor force. Specifically, the mean applicant on XMRC is 25 years old, while less than 20 percent of Xiamen's working population is under 25. And XMRC's applicants have over 14 years of education on average, while over 70 percent of Xiamen's workers have 12 or fewer years. One reason for this difference is the fact that any sample of jobseekers is likely to be younger than the stock of currently employed workers, combined with the massive recent expansion of higher education in China. ${ }^{13}$ Another reason is that young, highly educated workers are more likely to look for work on line than other workers (Kuhn and Skuterud 2004; Kuhn and Mansour, 2013). Overall, however, despite the fact that both the LH and NLH workers on our site are on average considerably more skilled than existing Xiamen workforce, the similarity of LH and NLH applicants in our sample should help us identify the pure effect of the applicant's official residency status on his or her success in the job search process.

\subsection{Methods}

Our sample for the analysis of employer callback decisions is the 237,128 applications summarized in Table 2. In this sample we estimate linear probability regressions for whether the applicant received a callback as a function of the characteristics of the firm placing the ad, the characteristics of the ad itself (primarily the stated job requirements and the employer's preferred employee demographics), the characteristics of the applicant, the match between the job's requirements and the applicant's characteristics, and the level of competition for the job (number of applicants and number of positions available). Thus, our approach is similar to that of correspondence studies (Bertrand and Mullainathan 2004; Oreopoulos 2011) in that we study firms' callback responses to a set of resumes, with some key differences. On the minus side, migrant status in our approach is not randomly assigned to resumes that are otherwise constructed to be as identical as possible; thus we need to rely on our extensive list of controls for ad and job characteristics. On the plus side, the population of naturally-occurring resumes in our sample avoids well known problems with audit studies, including the credibility of resumes and the tendency for those studies to focus on narrow ranges of occupations only, limiting their generalizability. In contrast to audit studies, we also observe the complete pool of applications submitted to a job (at least via $\mathrm{XMRC}$ ), not just the ads that are crafted and submitted by the investigator.

In all our regression tables, we present a series of specifications with increasingly detailed controls, the most saturated of which includes a fixed effect for every ad in the

\footnotetext{
${ }^{13}$ See Kuhn and Shen (2013) for some statistics on China's recent higher education boom.
} 
dataset. ${ }^{14}$ In that specification, our estimated coefficients compare the callback rates of LH and NLH workers who have applied to the same job, controlling for a long list of worker characteristics and their match with the advertised job requirements.

\section{Results}

Table 3 presents estimates of linear probability regressions in which the dependent variable equals one if the applicant was contacted by the firm's HR department after applying to the ad. ${ }^{15}$ Column 1 contains no regressors other than NLH; it replicates Table 2's finding that on average, NLH workers were 1.4 percentage points (or twenty percent) more likely to receive an employer contact than LH workers. Column 2 adds controls for basic characteristics of the job ad (specifically the requested levels of education, age, experience, gender, and whether a new graduate is sought), plus measures of the match between those characteristics and the worker's actual characteristics. ${ }^{16}$ Unsurprisingly, we find that workers with less than the required level of education and experience are less likely to receive a callback than workers who 'exactly' meet the firm's hiring criteria. ${ }^{17}$ Perhaps more surprisingly, workers who have more than the requested level of education are also less likely to be contacted. Workers outside the firm's advertised age range for the job are also less likely to be contacted, regardless of whether they are older or younger than the range. Having less than the required level of experience, and not being of the desired gender also reduce an applicant's chances of being contacted by the firm. ${ }^{18}$

Column 3 adds controls for a more detailed set of $\mathrm{CV}$ characteristics that are available in our data. These are whether the applicant attended a technical school, the applicant's zhicheng rank (6 categories) whether the CV is in English, the number of schools attended, the number of job experience spells, and the number of certifications reported. The following characteristics are also included, both as main effects and interacted with the applicant's gender: myopia, height, and marital status. Adding these detailed controls for the applicant's qualifications leaves the NLH coefficient essentially unchanged; the same is true when occupation fixed effects (for the job) are added in column 4.

\footnotetext{
14 This specification, of course, vitiates the need to control for job characteristics.

${ }^{15}$ Note that firms may contact more than one applicant for a job, either because they have not finalized the selection process or they are filling more than one vacancy. Recall also that applicants who were contacted via methods other than the website (such as telephone) will be treated as not being contacted in our data. This could be an issue if firms tend to use different methods to contact LH versus NLH workers. We explored this issue in discussions with XMRC officials, who stated that this was highly unlikely. The marginal financial cost of contacting an applicant anywhere in China is zero both by telephone and via the site, and recruiters generally find it easiest to issue all callbacks to the same job in the same way.

${ }^{16}$ In addition to the regressors shown in Table 3, columns 2-6 also include controls for the advertised wage and its 'match' with the applicant's current wage, and a dummy for whether this wage information is missing. The NLH coefficients are not affected by whether we include or exclude these controls.

${ }^{17}$ Education is measured in six broad categories, so an exact match simply means the same broad category. An exact experience match is defined as having the desired experience level or up to three years more.

${ }^{18} \mathrm{We}$ also ran regressions where we added controls for the total amount of over- and underqualification (and its square) on all these dimensions. The coefficients on hukou were very similar.
} 
Column 5 of Table 3 adds two indicators of the amount of competition for the job in question, specifically the number of positions available and the number of persons who applied to the ad. Both have strong effects in the expected directions but their inclusion does not change the NLH coefficient. Column 6 adds fixed effects for the firm that posted the ad. Once again, the NLH coefficient is essentially unchanged and remains highly statistically significant. Finally, column 7 adds a full set of job ad fixed effects; thus, as noted, we are now effectively comparing the success rates of LH and NLH workers who have applied to the same job ad. Again, the NLH coefficient is essentially unchanged from the previous column. Interestingly, the similarity of the column 6 and 7 results means that $\mathrm{NLH}$ workers do not disproportionately direct their applications to ads in which they are more likely to receive an employer contact. ${ }^{19}$ Instead, NLH workers seem to apply to the same mix of jobs, but achieve differential success when they get there.

In sum, Table 3 presents robust evidence that NLH workers have a higher chance of receiving an employer callback than observationally-equivalent LH workers when both groups of workers are competing for the same private-sector job. In the following section, we consider the plausibility of various explanations for this gap by exploring how the size of the gap varies across types of ads, firms and workers.

\section{What Explains Firms' Preferences for NLH Workers?}

\subsection{Discriminatory Tastes}

It is of course possible that employers, co-workers, or customers have differential tastes for interacting with migrant versus local workers. All available evidence, however, suggests that if anything Chinese urban residents are either indifferent or have some distastes for interacting with non-local workers (Dulleck, Fooken and He 2012; Tse 2014; Goerg and Chmura in progress). Since tastes of this nature should raise natives' hiring rates above migrants', they cannot explain employers' revealed preference for NLH applicants in our data. ${ }^{20}$

\subsection{Payroll tax differentials}

As noted, LH and NLH workers are treated differently by Xiamen's retirement and medical insurance programs. Specifically, LH workers and their employers contributed $8 \%$ and $14 \%$ of the worker's actual average monthly salary respectively to the retirement insurance program; for NLH workers these contributions are both 8

\footnotetext{
${ }^{19}$ Some search models of discrimination, such as Lang, Manove and Dickens (2005) have the property that in equilibrium, groups that anticipate encountering discrimination in the hiring process direct their search towards lower-wage jobs.

${ }^{20}$ That said, we do not expect high levels of taste-based discrimination in our sample, largely because a large majority (74 percent) of the NLH workers in our sample come from Fujian province, in which Xiamen is located. This similarity suggests that Xiamen's NLH workers might provide a cleaner test of the 'pure' effects of temporary residence status than studies of other temporary migrants, such as undocumented workers or H1-B visaholders in the U.S.
} 
percent of the monthly minimum wage (900 RMB). ${ }^{21}$ Similarly, LH workers and their employers contribute $2 \%$ and $7 \%$ respectively of their average actual monthly salary to medical insurance, while NLH workers and their employers each contribute $2 \%$ of the monthly minimum wage each month. ${ }^{22}$ As a result, NLH workers' combined retirement and medical payroll tax rate was about 44 percent of LH workers' rate near bottom of the earnings distribution in our sample (specifically, at 1500RMB per month). This tax advantage increases monotonically with the level of monthly earnings: near the top of the earnings distribution (at 5000RMB/month), NLH workers incurred only 16 cents of tax for every 100 cents paid by LH workers. ${ }^{23}$

Theoretically, the effect of differential payroll taxes on the relative callback rates of LH and NLH workers depends on whether firms can wage discriminate on the basis of residency status. If they can, the payroll tax gap should have no effect, since employers can simply adjust wages to compensate for any gap. ${ }^{24}$ If firms' ability to wage discriminate between native and migrants is limited, however, firms should prefer NLH applicants to equally qualified LH applicants. ${ }^{25}$ Moreover, due to the structure of payroll taxes in Xiamen, the strength of these preferences should increase with a job's skill requirements.

To assess this hypothesis, Table 4 estimates a different effect of NLH status for each of the five levels of required education for the job, while Table 5 does the same for six different advertised wage levels. For both wages and education levels we find the opposite pattern from what is predicted by NLH workers' payroll tax advantage: firms' revealed preferences for NLH workers are considerably stronger at low skill levels than higher ones. This pattern is more pronounced across wage than education levels: while the NLH advantage is present in all education groups except university graduates, it is confined to jobs offering under 3000 yuan per month. Firms recruiting for very highwage jobs, where NLH workers' payroll tax advantage is the highest, do not have a systematic preference for NLH workers. Given these patterns, which are inconsistent with a payroll tax-based explanation, we consider other possible explanations of firms' NLH preference below.

\footnotetext{
${ }^{21}$ LH workers' retirement- and UI-taxable earnings are capped at three times the city average wage (9114RMB/month); less than one percent of the ads or workers in our data are affected by this cap.

${ }^{22}$ Informally, the rationale for these differentials seems to be to mimic benefit levels in migrants' home regions, which are generally much lower than in the coastal cities. In addition, as one local official expressed, the number of migrant workers is so large and many of them will never use retirement and medical insurance benefits due to their age structure and migration pattern.

${ }^{23}$ Some of these tax policies have been adjusted since our data was collected, partly in response to a perception that they negatively affected some LH workers' employment prospects. Specifically, Xiamen's government recently moved in the direction of eliminating payroll tax differentials between LH and NLH workers by granting NLH payroll tax rates to firms hiring 'employment-disadvantaged' LH workers, LH new college graduates, and LH workers in public service jobs.

${ }^{24}$ The extent to which this wage discrimination actually hurts native workers depends on the extent to which they value the additional social benefits attached to their higher tax rates (Summers 1989).

${ }^{25}$ Notice also that if firms cannot wage-discriminate, only the employer's share of the payroll tax should affect their decision on whom to hire. Incidentally, adjusting offered wages to cancel out the LH/NLH payroll tax differential is explicitly prohibited in Xiamen, and is subject to large fines.
} 


\subsection{Wage differentials}

If NLH workers' lower tax cost cannot explain their callback advantage, what about their relative wage costs? Is it possible that firms systematically prefer NLH applicants simply because they can hire them for a lower wage? In this section we describe two ways in which a wage gap might account for the NLH hiring advantage. They are based on the possibility of LH-NLH wage differentials between jobs (i.e. ads), and within jobs, respectively.

Turning first to between-job wage variation, one scenario that might account for a higher NLH hiring rate is a situation where NLH workers disproportionately apply to lower-wage jobs and where lower-wage jobs, on average, are easier to get (i.e. they have higher callback rates). A closely related possibility is a scenario where firms engaging in monopsonistic wage discrimination (or, for that matter, firms who want to protect native workers' wages while still benefiting from cheaper migrant labor) create distinct job categories tailored to the two groups. ${ }^{26}$ If migrants apply mostly to the lower-wage categories where the hiring rate is higher, that could account for our main result.

While these seem like plausible scenarios, they are not likely explanations for the NLH hiring advantage in our data for at least two reasons: First, all our estimates control for the level of both the advertised wage and the applicant's current wage. ${ }^{27}$ Second, if firms wage-discriminate against NLH workers by posting separate (lower-wage) job ads specifically tailored to them, then the estimated NLH hiring advantage should decline in size when we replace the firm fixed effects in column 6 of Table 3 by job ad fixed effects in column 7. As already noted, they do not. Put a different way, the fact that the NLH hiring advantage persists within ads rules out explanations based on the idea that NLH workers disproportionately apply to lower-wage jobs, which may be easier for them to get.

Next we turn to the possibility of within-job wage discrimination, i.e. the possibility that firms might prefer NLH workers over LH workers who have applied to the same job, if they can subsequently hire the NLH worker for a lower wage. While we cannot measure the amount of within-job wage discrimination directly, it seems likely that this type of discrimination is more difficult in posted-wage jobs than in jobs where the wage is not specified in the ad. ${ }^{28}$ If that is the case, then firms' preferences for NLH workers should be weaker in posted-wage jobs.

\footnotetext{
${ }^{26}$ Wage discrimination against migrants can be profit-maximizing if migrants supply labor less elastically to the firm. See for example Hotchkiss and Quispe-Agnoli (2009), Hirsch and Jahn (2012), and Depew et al (2013).

${ }^{27}$ Strictly speaking, the estimates in Table 3 only control for the advertised and current wage when each variable is available in the data (which is the case for 59 and 69 percent of applications respectively). The results are very similar, however, when we estimate the Table 3 on the subsample of observations where both variables are present.

${ }^{28}$ Note that within-job wage discrimination is typically ignored in correspondence studies, which cannot ascertain whether different wages would be offered to different types of candidates at the interview stage or later.
} 
To examine this hypothesis, Table 6 estimates separate NLH effects on callback rates to job ads with and without posted wages, using the same regression specifications as Tables 3-5. As it turns out, the NLH hiring advantage is greater in posted-wage jobs in some specifications, and lower in others, and the difference between posted- and nonposted-wage jobs is never statistically significant at conventional levels ( $p$-values are reported in the bottom row of the Table). We interpret this as evidence against within-job wage discrimination as the primary reason why firms exhibit a preference for NLH workers. We also note that a widespread and robust feature of job board data, including the data in this paper, is that wage posting is much more common in unskilled than skilled jobs. ${ }^{29}$ If the disproportionate use of posted wages in unskilled jobs indicates a greater overall reluctance by firms to engage in individual wage negotiation in lessskilled jobs, a scenario based on within-job wage discrimination faces challenges in explaining why the NLH hiring advantage is greatest in the least-skilled jobs. Relative to skilled jobs, wages in those jobs are more likely to be set by inflexible rules than by individual negotiation.

\subsection{Selection}

Another reason why similarly-qualified migrants might be preferred to locals is selection: While we have a detailed set of controls, and while our LH and NLH samples have very similar observable characteristics, it is still possible that migrants have, on average, higher unobserved skills. That said, selection on unobservables faces at least two challenges as an explanation of the NLH advantage in our data. First, note that even if migrants are positively selected relative to stayers in their home regions -as one would expect, for example, from Borjas's (1987) selection model when there is more inequality in the receiving region--, this type of positive selection does not necessarily imply that migrants will be more productive than natives with identical observables. Second, if anything, we would probably expect NLH workers to suffer deficits in education quality, connections (guanxi) and other destination-specific skills, which would all appear as negative selection on unobservables in our data.

Still, we acknowledge that positive selection on unobservables could be part of the reason why NLH workers are more likely to receive employer callbacks than LH workers in our data. Persons who choose to migrate to a city, especially in a capacity where their temporary residence status excludes them from key components of the public goods and social protections available to urban natives, are likely to have a stronger work ethic than their compatriots who remain behind.

\subsection{Hours and Effort}

A final potential explanation of the NLH callback advantage is the possibility that migrants and natives of identical ability differ in their effort and labor supply choices in a

\footnotetext{
${ }^{29}$ See for example Brencic (2012) and Delgado Helleseter, Kuhn and Shen (2014).
} 
way that makes migrants more desirable to employers. ${ }^{30}$ One possible source of such a gap emerges from intertemporal labor supply models: to the extent that NLH workers face a significant prospect of returning to their (low-wage) region of origin, NLH workers face a wage that is temporarily high relative to other points in their lifetime. This creates an intertemporal substitution effect that should raise migrants' work hours and effort relative to natives' at the same wage (Dustmann 2000). This prediction of longer work hours among migrants is strongly supported by the Census data presented in Table 1.

A second possible source of a migrant-native effort gap is an efficiency wage effect: to the extent that migrants' outside options are poorer than natives', migrants should be willing to exert more effort to keep their jobs. This will certainly be the case if migrants' outside options consist primarily of jobs in their home regions, but may apply even if it is relatively easy for migrants to change jobs within the host city. One reason is that migrants are excluded from some key components of the urban social safety net. (Recall from Table 1 that NLH workers in Xiamen are much less likely to have unemployment and medical insurance coverage). In addition, migrants probably have less wealth (including owned housing) than natives, and Table 1's employment statistics suggest that migrants are excluded from a number of attractive, secure public sector and SOE employment options that are available to natives. Finally, note that the LH-NLH gap in social insurance coverage is probably most relevant to workers' outside options at low skill levels, which is precisely where employers have the strongest revealed preference for NLH workers. ${ }^{31}$

To explore the possible role of intertemporal labor supply effects, Table 7 provides separate estimates of the NLH hiring advantage by applicant gender and marital status. The idea is to compare groups who potentially have more flexibility to work extremely long hours and at high intensity (men and single women) to a group that might be less able to do so (married women). If the flexibility to work long, intense hours explains why firms prefer NLH workers, we might expect to see a smaller NLH advantage among married women than among other groups. Interestingly, in the absence of controls (column 1) we find that the NLH advantage is indeed statistically significant for men and for single women, but insignificant for married women. Further, men's NLH advantage is twice as large as women's, and the gap between men's and married women's NLH advantage is highly statistically significant. In the most saturated specification (column 7), the same pattern of statistical significance appears, but a very noisy estimate for married women makes it impossible to conclude that they have a lower

\footnotetext{
${ }^{30}$ In general, firms will prefer workers who choose higher effort levels, or who will accept additional work hours, whenever employment contracts are incomplete, i.e. as long as the pay rate per hour or piece gives workers less than $100 \%$ of the surplus they generate at the margin.

${ }^{31}$ Another aspect of worker performance that might differ between LH and NLH workers is their expected turnover rate. While it is unclear whether we would expect LH or NLH workers turn over more frequently in the short run, the fact that hukou regulations make it difficult to settle down and raise a family suggests that firms wishing to hire long-term workers might prefer LH workers. To the extent that firm-specific human capital is complementary with education and other indicators of general skills, this could also help explain why we estimate a weaker NLH preference at higher skill levels.
} 
NLH advantage. In part, this is because married women constitute only 6.7 percent of our sample of NLH applicants, compared to 47.7, 36.5 and 9.3 for single women, single men and married men respectively. We view this as suggestive, but weak evidence that the NLH advantage in our data is driven disproportionately by men and single women, who may have more flexibility to provide longer work hours and intense work effort than married women. ${ }^{32}$

In Figure 1 and Table 8, we explore a prediction that is shared by the intertemporal labor supply and efficiency wage explanations of the NLH callback advantage. Specifically, if a worker's outside options in the event of job loss consist, at least in part, of working in her home province, then NLH workers who come from lowwage provinces should have stronger work incentives in the city than NLH workers from richer provinces. Similarly, intertemporal labor supply effects should be stronger for workers from poor than rich provinces. Thus, both hypotheses predict that --holding worker qualifications and job characteristics constant - employers should prefer NLH workers from poor provinces to NLH workers from rich provinces. Note that both these predictions contrast with the predictions of simple human capital models, which suggest that the lower quality of education, poorer health, and lower familiarity with modern work practices in poorer regions would hurt those residents' employment prospects in Xiamen.

Figure 1 shows the unadjusted GDP-NLH advantage relationship in our data graphically, showing very high callback rates for applicants from China's two poorest provinces -Guizhou and Yunnan--, low callback rates from richer areas like Guangdong and Inner Mongolia, and almost no applicants to jobs in Xiamen from the richest provinces: Beijing, Shanghai and Tianjin. The linear regression line in the Figure shows a clear negative relationship between per-capita GDP in the sending region and workers' callback rates from employers in Xiamen. To quantify this relationship, Table 8 adds three regressors to our baseline specification in Table 3. The first is a fixed effect for whether the NLH applicant is not from Fujian (the province in which Xiamen is located); this allows us to see whether interprovincial applicants, as a group, are treated differently from intraprovincial ones. ${ }^{33}$ The next two variables interact interprovincial migrant status with the distance of the applicant's home province from Fujian and its level of per capita income.

\footnotetext{
${ }^{32}$ We also explored the effects of the applicant's age, interacted with gender, as a crude proxy for whether the NLH advantage was lower among women who are likely to have children. We found that the NLH callback advantage is higher among workers in the 'prime' ages for temporary migration to cities (22-34) than in other age groups for both men and women. Within this age range, the NLH advantage is smallest among women aged 22-27, which is consistent with the idea that flexibility to work long, hard hours plays a role in the NLH advantage.

${ }^{33}$ Intraprovincial migrants might have different outcomes since some of these applicants come from suburban and rural areas that are very close to the city of Xiamen, some of whom could commute to jobs in the city.
} 
Consistent with efficiency-wage and intertemporal labor supply interpretations of the NLH advantage, row 3 of Table 8 shows that the NLH callback advantage decreases with the origin province's per capita GDP, reflecting the pattern in Figure 1. While not statistically significant in every specification, this effect is significant (at 10 percent) in the absence of controls (column 1) and in the most saturated specification (column 7), which includes job ad fixed effects. Row 2 of Table 8 also shows a larger NLH hiring advantage for interprovincial applicants than for applicants from Xiamen's own province, but this advantage disappears and becomes statistically insignificant in the presence of firm or job ad fixed effects. Similar results, but with larger magnitudes, are present in Panel B of Table 8, which replicates Panel A for less-skilled jobs only (specifically, for ads requiring high school or less), where we have shown that firms' NLH preference is strongest. Here, the coefficient on per capita GDP in the migrant's home region is statistically significant in a larger share of the specifications, though it is not in column 7 , where job ad fixed effects are present. Panel $\mathrm{C}$ focuses on skilled jobs. As expected, it shows a much smaller NLH advantage, and no effects of origin-region GDP can be identified.

Overall, we see Table 8's results as supportive of both the efficiency wage and intertemporal labor supply interpretations of the NLH hiring advantage. Especially given the fact that applicants from poorer regions are likely less qualified on a number of unobservable dimensions, we find it highly suggestive that employers seem to prefer nonlocal applicants from poorer provinces to applicants from richer provinces.

\section{Discussion}

To our knowledge this is the first paper to study employers' hiring choices between equally-qualified workers with and without permanent residence permits in the region of employment. Our main finding is that despite evidence of taste-based discrimination against NLH persons from other studies (e.g. Dulleck, Fooken and He 2012), and despite the fact that NLH workers likely have lower levels of transferable, unobserved skills than natives, employers in our data are more likely to call back identically-matched NLH than LH applicants to the same job. Because this preference is much stronger when firms are seeking to fill less-skilled positions, it cannot be explained by payroll tax differences between LH and NLH workers. Explanations based on between-job wage discrimination are ruled out by job ad fixed effects, while a within-ad wage discrimination scenario is hard to reconcile with the fact that the NLH preference does not differ between posted-wage and non-posted wage ads.

Another candidate to explain the callback gap in our data is selection:

unregistered migrants may be more qualified than local-hukou workers. While we expect that positive selection probably plays some role in explaining the NLH callback advantage, we note that a purely selection-based story faces some challenges. One is that our detailed measures of observable skills show only very small differences between migrants and natives, most of which favor natives, not migrants. Thus, a selection-based 
explanation would require a different selection pattern on observables than observables, and would require this selection pattern to be confined to less-skilled workers. Most importantly, to explain the NLH callback advantage vis-à-vis natives in our data, positive selection among migrants would need to be strong enough to outweigh migrants' likely disadvantages in education quality and health in the poorer regions they come from.

The above discussion suggests that explanations based on different choices made by NLH versus LH workers in the destination city - such as work hours and effort levels-deserve serious consideration. Indeed, both life cycle labor supply models and efficiency wage models provide theoretical reasons to expect NLH workers to work longer and harder than natives at the same wage while they are in the destination city. These predicted differences in labor supply are strongly supported by Census data on work hours and employment rates. Further, NLH workers' low social insurance coverage provide a natural reason to expect a larger efficiency wage effect at low skill levels. Additional support comes from evidence that employers' NLH preferences are weakest among married women (who may have less flexibility to work long, hard hours), and strongest for NLH workers from China's poorest provinces. Indeed, the negative relation between source-province GDP per capita and firms' preferences for migrant workers strikes us as especially supportive of efficiency wage and intertemporal labor supply mechanisms, because if anything we would expect workers coming from poorer regions to have lower levels of unobserved skills.

While we believe the above findings are thought-provoking, we also emphasize that they should be interpreted with a number of important caveats in mind. One is the fact that -as in all correspondence studies-- our dependent variable measures callbacks only, not whether a worker ultimately receives a job offer. As a result, our main result could be in jeopardy if firms systematically make fewer offers per callback to NLH than LH workers, provided they do this more at low skill levels than high ones. While we cannot rule this out, it is hard to think of plausible reasons why callback and offer patterns might differ in this way. ${ }^{34}$

Second, recall that our sample of applicants is restricted to people who have chosen to search for work online, and on XMRC.com specifically. Thus, our main result could also be explained by differential selection into online job search, if this selection is more positive among NLH than among LH workers. While this is possible, we note again that it would require a different pattern of selection on unobservables than

\footnotetext{
${ }^{34}$ A key source of the difficulty is that most unobserved factors that could affect callback rates should theoretically affect offer rates conditional on callbacks in the same direction. For example, suppose (as seems likely) that NLH workers' productivity is harder to predict than natives. In that case, their higher option value suggests that employers should not only interview more of them, but make more job offers to them as well (Lazear 1995). The same should apply if NLH workers are more likely to accept a job offer than LH applicants: both callbacks and offers should be higher, with no clear prediction for the ratio of offers to callbacks. Equally challenging is identifying factors that affect callback and offer rates differently, but only for less-skilled workers. In contrast, there are clear reasons to expect stronger efficiency wage and intertemporal labor supply effects among less skilled NLH workers compared to skilled ones.
} 
observables. In addition, this difference in selection into online search would have to be confined to low skill levels to explain our result. Finally, we note that Kuhn and Skuterud (2004) find evidence of negative, not positive selection into internet job search on unobservables.

Third, recall that XMRC serves private-sector employers almost exclusively; thus our results say nothing about the preferences of public-sector employers and state-owned enterprises, which -as we have noted - are much more likely to employ LH than NLH workers. In fact, since public sector and SOE jobs are sometimes explicitly reserved for LH workers in China, our results are consistent with a segmented labor markets scenario in which -holding match quality fixed-- private-sector employers tend to prefer NLH workers, while public service and SOE employers prefer LH workers. Indeed, the latter sectors, which are generally not exposed to significant competitive pressures in product markets, may play an important role in sheltering native workers from competition with the massive influx of migrants in many Chinese cities. ${ }^{35}$

Fourth, the generality of our results is limited by the fact that Chinese NLH workers differ in important ways from workers with insecure or limited residency rights in other jurisdictions. For example, unlike undocumented workers in the U.S., employed NLH workers are not at risk of summary deportation. This might make NLH workers more desirable employees than someone who could disappear unexpectedly as a result of and Immigration and Customs Enforcement raid. Also, in contrast to U.S. undocumented workers and to temporary visa-holders in many countries, the NLH workers in our sample are relatively similar in language, culture and ethnicity to locals; as noted, most of them come from Fujian province, in which Xiamen is located. The NLH applicants in our sample also have a very similar skill distribution to local applicants. This contrasts starkly to undocumented workers and holders of temporary visas in the United States, who tend to occupy the tails of the skill distribution. Taken together, these similarities in culture and skills between Xiamen's LH and NLH workers suggest that that our results may come closer than other comparisons to isolating the 'pure' effect of workers' insecure residency rights on firms' recruiting decisions. Perhaps paradoxically, our main finding is that --at least at low skill levels-- limited residency rights appear to make workers more attractive to employers.

\footnotetext{
${ }^{35}$ House (2012) documents a similar, though more extreme phenomenon in Saudi Arabia, where 90 percent of private-sector jobs are held by foreigners, while natives either work in the public sector or not at all.
} 


\section{References}

Aimeiaishenghu. "Outsiders can do a taxi driver in Beijing” Wenda.com, May 20, 2013 http://finance.ifeng.com/money/wealth/story/20100423/2095640.shtml (accessed April 22, 2014)

Aluminum Corporation of China, "2012 college graduates recruitment notice" Yingjiesheng.com, January 16, 2012. http://www.yingjiesheng.com/job-001-253-682.html (accessed April $22,2014)$

Bao, Shuming, Orn B. Bodvarsson, Jack W. Hou and Yaohui Zhao "The Regulation of Migration in a Transition Economy" IZA discussion paper no. 4493, October 2009.

Barcellos, Silvia H. "Legalization and the Economic Status of Immigrants" RAND working paper no. WR-754, March 2010.

Bertrand, Marianne, and Sendhil Mullainathan, "Are Emily and Greg More Employable Than Lakisha and Jamal? A Field Experiment on Labor Market Discrimination,'” American Economic Review, 94 (2004), 991-1013.

Bodvarsson, Orn B., Jack W. Hou and Kailing Shen. "Aging and Migration in a Transition Economy: The Case of China”, WISE working paper, 2014.

Borjas, George. "Self-Selection and the Earnings of Immigrants" American Economic Review. September 1987; 77(4): 531-53.

Borjas, G.J. and M. Tienda. 1993. "The Employment and Wages of Legalized Immigrants." International Migration Review 27(4):712-747.

Brencic, Vera. "Wage Posting: Evidence from Job Ads" Canadian Journal of Economics 45(4) (Nov 2012): 1529-1559.

Chan, Kam Wing and Will Buckingham. "Is China Abolishing the Hukou System?" The China Quarterly 195, September 2008: 582-606

Depew, Briggs, Peter Norlander, and Todd Sorensen. "Flight of the H-1B: Inter-Firm Mobility and Return Migration Patterns for Skilled Guest Workers" IZA Discussion Paper No. 7456, June 2013.

Démurger, Sylvie and Hui Xu. "Left-Behind Children and Return Decisions of Rural Migrants in China” IZA discussion paper no. 7727 (November 2013).

Dulleck, Uwe, Jonas Fooken and Yumei He. 2012. "Public Policy and Individual Labor Market Discrimination: An Artefactual Field Experiment in China”. Unpublished paper, Queensland University of Technology.

Dustmann, Christian. 2000. "Temporary Migration and Economic Assimilation" Swedish Economic Policy Review 7(2): 213-244.

Goerg, Sebastian and Thorsten Chmura. "Gift exchange with migrant workers and students in China" work in progress, Florida State University. 
Hirsch, Boris, and Elke Jahn. “Is There Monopsonistic Discrimination Against Immigrants?” IZA discussion paper no. 6472, April 2012.

Hotchkiss, Julie L. and Myriam Quispe-Agnoli, "Employer Monopsony Power in the Labor Market for Undocumented Workers," SSRN eLibrary, December 2009.

House, Karen Elliott. On Saudi Arabia : its people, past, religion, fault lines--and future New York, Knopf, 2012.

Huang, Xiuli. "Beijing Lawyers are not welcome foreign lawyers" Edu.ifeng.com, April 23, 2010. (accessed April 22, 2014)

Kossoudji, S.A. and D.A. Cobb-Clark. 2002. "Coming out of the Shadows: Learning about Legal Status and Wages from the Legalized Population.” Journal of Labor Economics 20(3): 598-628.

Kuhn, Peter and Kailing Shen. 2013. "Do Chinese Employers Avoid Hiring Overqualified Workers? Evidence from an Internet Job Board” Research in Labor Economics 37: 1-30.

Kuhn, Peter, Miguel Delgado Helleseter, and Kailing Shen. 2014. "Employers' Age and Gender Preferences: Direct Evidence from Four Job Boards" unpublished paper, UCSB.

Kuhn, Peter and Mikal Skuterud. ““'Internet Job Search and Unemployment Durations” American Economic Review 94(1) (March 2004): 218-232.

Kuhn, Peter and Hani Mansour, "Is Internet Job Search Still Ineffective?" Economic Journal, forthcoming 2014.

Lang, K., M. Manove, and W. T. Dickens. "Racial Discrimination in Labor Markets with Posted Wage Offers”. American Economic Review September 2005; 95(4): 1327-40.

Lazear, E. P. (1995). Hiring risky workers National Bureau of Economic Research, Inc, NBER Working Papers: 5334.

Oreopoulos, Philip. "Why Do Skilled Immigrants Struggle in the Labor Market? A Field Experiment with Thirteen Thousand Resumes" American Economic Journal: Economic Policy 4 (Nov 2011): 148-171.

Rivera-Batiz, F.L. 1999. "Undocumented Workers in the Labor Market: An Analysis of the Earnings of Legal and Illegal Mexican Immigrants in the United States." Journal of Population Economics 12(1): 91-116.

Summers, L.H. "Some Simple Economics of Mandated Benefits", American Economic Review 79 (May 1989): 177-183.

Tse, Chun-Wing "Urban Residents' Discrimination and Well-Being of Rural-to-Urban Migrants in China" unpublished paper, Central University of Finance and Economics, Beijing, 2014.

Xiamen News Net (August 27, 2013) "Xiamen: hundreds of people took to the streets because of their children to school probems" http://fj.qq.com/a/20130827/014835_all.htm. (accessed April 18,2014). 
Table 1: Employment Statistics by Hukou and Current Residence, 2005 Census

All Urban Residents in Major Cities

A. ALL WORKING-AGE PERSONS

$\begin{array}{cc}\text { With } & \text { With } \\ \text { cal Hukou } & \text { Non-local Hukou }\end{array}$

\begin{tabular}{cc} 
Residents of Xiamen \\
\hline With & With \\
Local Hukou & Non-local Hukou
\end{tabular}

\begin{tabular}{|c|c|c|c|c|}
\hline & (1) & (2) & (3) & (4) \\
\hline \multicolumn{5}{|l|}{ Age } \\
\hline $18-25$ & $9 \%$ & $15 \%$ & $12 \%$ & $18 \%$ \\
\hline $26-35$ & $21 \%$ & $33 \%$ & $27 \%$ & $42 \%$ \\
\hline $36-45$ & $28 \%$ & $26 \%$ & $28 \%$ & $24 \%$ \\
\hline $46-55$ & $28 \%$ & $17 \%$ & $23 \%$ & $12 \%$ \\
\hline $56-65$ & $13 \%$ & $8 \%$ & $10 \%$ & $3 \%$ \\
\hline \multicolumn{5}{|l|}{ Education } \\
\hline Primary (6 years or less) & $7 \%$ & $20 \%$ & $21 \%$ & $26 \%$ \\
\hline Junior Middle School (9 years) & $31 \%$ & $44 \%$ & $25 \%$ & $40 \%$ \\
\hline High School (12 years) & $34 \%$ & $21 \%$ & $27 \%$ & $21 \%$ \\
\hline Junior Technical School (15 years) & $16 \%$ & $8 \%$ & $13 \%$ & $7 \%$ \\
\hline University Degree (16 years or more) & $12 \%$ & $7 \%$ & $14 \%$ & $5 \%$ \\
\hline \multicolumn{5}{|l|}{ Employment status } \\
\hline employed & $62 \%$ & $77 \%$ & $68 \%$ & $83 \%$ \\
\hline not employed & $38 \%$ & $23 \%$ & $32 \%$ & $17 \%$ \\
\hline \multicolumn{5}{|l|}{ Sources of income } \\
\hline labor market & $61 \%$ & $76 \%$ & $67 \%$ & $81 \%$ \\
\hline public transfers & $23 \%$ & $6 \%$ & $13 \%$ & $3 \%$ \\
\hline capital income & $3 \%$ & $3 \%$ & $3 \%$ & $2 \%$ \\
\hline family members & $13 \%$ & $15 \%$ & $16 \%$ & $14 \%$ \\
\hline \multicolumn{5}{|l|}{ Social insurance coverage } \\
\hline UI covered & $44 \%$ & $18 \%$ & $38 \%$ & $21 \%$ \\
\hline pension covered & $72 \%$ & $31 \%$ & $60 \%$ & $30 \%$ \\
\hline medical insurance covered & $69 \%$ & $42 \%$ & $73 \%$ & $39 \%$ \\
\hline Share of the population & $49 \%$ & $51 \%$ & $44 \%$ & $56 \%$ \\
\hline
\end{tabular}


Table 1, continued

\begin{tabular}{|c|c|c|c|c|}
\hline \multirow[b]{2}{*}{ B. WORKERS ONLY } & \multicolumn{2}{|c|}{ All Urban Residents in Major Cities } & \multicolumn{2}{|c|}{ Residents of Xiamen } \\
\hline & $\begin{array}{c}\text { With } \\
\text { Local Hukou }\end{array}$ & $\begin{array}{c}\text { With } \\
\text { Non-local Hukou }\end{array}$ & $\begin{array}{c}\text { With } \\
\text { Local Hukou }\end{array}$ & $\begin{array}{c}\text { With } \\
\text { Non-local Hukou }\end{array}$ \\
\hline & (1) & (2) & (3) & (4) \\
\hline $1-39$ hours & $4 \%$ & $8 \%$ & $8 \%$ & $6 \%$ \\
\hline 40 hours & $66 \%$ & $35 \%$ & $47 \%$ & $21 \%$ \\
\hline 41-56 hours & $23 \%$ & $39 \%$ & $33 \%$ & $41 \%$ \\
\hline public sector & $21 \%$ & $7 \%$ & $21 \%$ & $4 \%$ \\
\hline SOE ( includes collectives) & $41 \%$ & $15 \%$ & $23 \%$ & $11 \%$ \\
\hline self employment & $11 \%$ & $24 \%$ & $13 \%$ & $25 \%$ \\
\hline private enterprise & $23 \%$ & $32 \%$ & $31 \%$ & $43 \%$ \\
\hline other & $5 \%$ & $23 \%$ & $13 \%$ & $17 \%$ \\
\hline \multicolumn{5}{|l|}{ Nature of work contract } \\
\hline \multicolumn{5}{|l|}{ Duration of contract if fixed term } \\
\hline 1 year or below & $59 \%$ & $73 \%$ & $62 \%$ & $71 \%$ \\
\hline 1-2 years & $12 \%$ & $10 \%$ & $13 \%$ & $10 \%$ \\
\hline $2-3$ years & $19 \%$ & $11 \%$ & $21 \%$ & $12 \%$ \\
\hline more than 3 years & $9 \%$ & $6 \%$ & $5 \%$ & $6 \%$ \\
\hline Share of the population & $43 \%$ & $57 \%$ & $39 \%$ & $61 \%$ \\
\hline
\end{tabular}

Note: Data are from the 2005 Census of China, 1\% sample, persons aged 15-65, healthy, current living in urban regions, excluding students. All rural hukou individuals are regarded as without local hukou in the urban area. Major cities are the 4 municipalities directly under the jurisdiction of the central government (Beijing, Shanghai, Tianjing and Chongqing) and the 15 subprovincial cities. Xiamen is one of the 15 subprovincial cities. 


\section{Table 2: Sample Means by Applicant's Hukou Status, XMRC Data}

\begin{tabular}{|c|c|c|}
\hline a. Contacted by HR department & 0.071 & 0.085 \\
\hline \multicolumn{3}{|l|}{ b.Characteristics of the Applicant: } \\
\hline Education (years) & 14.42 & 14.38 \\
\hline Age (years) & 25.95 & 24.58 \\
\hline Experience (years) & 4.09 & 3.15 \\
\hline New Graduate? & 0.131 & 0.191 \\
\hline Female & 0.594 & 0.542 \\
\hline Current wage listed? & 0.686 & 0.689 \\
\hline Current wage, if listed (yuan/month) & 2313 & 2263 \\
\hline Completed Tech School? & 0.315 & 0.158 \\
\hline Married & 1.126 & 1.195 \\
\hline Occupational Qualification (Zhicheng) & 0.336 & 0.299 \\
\hline Myopic & 165.5 & 165.6 \\
\hline Height $(\mathrm{cm})$ & 0.129 & 0.127 \\
\hline English CV as well? & 0.838 & 0.783 \\
\hline Number of Schools listed in the CV & 2.720 & 2.417 \\
\hline Number of Experience Spells described in the CV & 1.383 & 1.178 \\
\hline Number of Certifications & 14.42 & 14.38 \\
\hline \multicolumn{3}{|l|}{ c. Characteristics of the Job Ad: } \\
\hline Education Requested (years) & 12.68 & 12.53 \\
\hline Desired Age Range specified? & 0.546 & 0.536 \\
\hline Desired Age, if Requested (midpoint of interval) & 27.45 & 27.08 \\
\hline Experience Requested & 1.022 & 0.932 \\
\hline New Graduate Requested? & 0.048 & 0.045 \\
\hline Male Applicants Requested? & 0.127 & 0.132 \\
\hline Female Applicants Requested? & 0.326 & 0.297 \\
\hline Wage Advertised? & 0.568 & 0.588 \\
\hline Wage, if advertised (yuan/month, midpoint of interval) & 2324 & 2372 \\
\hline Number of positions advertised & 1.893 & 2.130 \\
\hline Number of applicants & 182.1 & 192.0 \\
\hline \multicolumn{3}{|l|}{ d. Characteristics of the Firm Placing the Ad: } \\
\hline Domestically Owned & 0.692 & 0.728 \\
\hline Taiwan, Hong Kong Ownership & 0.095 & 0.085 \\
\hline Foreign Owned & 0.160 & 0.146 \\
\hline Other (e.g. non-profits) & 0.053 & 0.041 \\
\hline Xiamen Firm Location & 0.969 & 0.970 \\
\hline Fujian Firm Location & 0.026 & 0.026 \\
\hline Other Firm Location & 0.005 & 0.004 \\
\hline Number of Employees & 634 & 556 \\
\hline e. Sample Size & 19,314 & 217,814 \\
\hline
\end{tabular}

Note: LH-NLH gaps in Current wage listed, English CV, Xiamen Firm Location, Fujian Firm Location are not statistically significant. Height differs at the $10 \%$ level; New graduate requested and Male Applicant requested, and Other firm location differs at 5\% and all remaining variables at 1\%. Zhicheng level is an integer ranging from 1 to 6. LH in Table 2 and throughout our main analysis denotes Xiamen city hukou only; workers with Fujian province (but not Xiamen) hukou are treated as NLH because their legal status in the city is the same as workers from other provinces. 
Table 3: Effects of Non-Local Hukou on the Probability of Employer Contact, Linear Probability Models

\begin{tabular}{|c|c|c|c|c|c|c|c|}
\hline & (1) & (2) & (3) & (4) & (5) & (6) & (7) \\
\hline \multirow{2}{*}{ Non-Local Hukou (NLH) } & $.0140 * * *$ & $.0125 * * *$ & $.0114 * * *$ & $.0100 * * *$ & $.0117 * * *$ & $.0082 * * *$ & $.0080 * * *$ \\
\hline & $(.0028)$ & $(.0026)$ & $(.0025)$ & $(.0024)$ & $(.0023)$ & $(.0019)$ & $(.0019)$ \\
\hline \multirow[t]{2}{*}{ Education less than requested } & & -.0067 & $-.0133 * *$ & $-.0130 * *$ & $-.0122 * *$ & $-.0103 * * *$ & $-.0101 * * *$ \\
\hline & & $(.0049)$ & $(.0055)$ & $(.0052)$ & $(.0053)$ & $(.0026)$ & $(.0025)$ \\
\hline \multirow[t]{2}{*}{ Education more than requested } & & -.0043 & .0016 & .0000 & -.0005 & .0020 & .0021 \\
\hline & & $(.0031)$ & $(.0038)$ & $(.0037)$ & $(.0038)$ & $(.0017)$ & $(.0016)$ \\
\hline \multirow[t]{2}{*}{ Age less than requested ${ }^{1}$} & & -.0008 & -.0025 & -.0025 & -.0003 & $-.0096 * * *$ & $-.0120 * * *$ \\
\hline & & $(.0058)$ & $(.0058)$ & $(.0058)$ & $(.0052)$ & $(.0033)$ & $(.0032)$ \\
\hline \multirow[t]{2}{*}{ Age more than requested ${ }^{1}$} & & $-.0292 * * *$ & $-.0270 * * *$ & $-.0255 * * *$ & $-.0157 * *$ & $-.0211 * * *$ & $-.0264 * * *$ \\
\hline & & $(.0087)$ & $(.0088)$ & $(.0084)$ & $(.0074)$ & $(.0071)$ & $(.0076)$ \\
\hline \multirow[t]{2}{*}{ Experience less than requested $^{2}$} & & -.0067 & -.0070 & -.0076 & $-.0103 * *$ & $-.0110 * * *$ & $-.0112 * * *$ \\
\hline & & $(.0057)$ & $(.0057)$ & $(.0054)$ & $(.0052)$ & $(.0025)$ & $(.0025)$ \\
\hline \multirow[t]{2}{*}{ Experience more than requested ${ }^{2}$} & & .0003 & -.0003 & -.0007 & -.0003 & -.0016 & -.0015 \\
\hline & & $(.0032)$ & $(.0028)$ & $(.0027)$ & $(.0026)$ & $(.0017)$ & $(.0016)$ \\
\hline \multirow[t]{2}{*}{ Wage below advertised ${ }^{3}$} & & .0004 & -.0001 & -.0009 & -.0019 & -.0005 & .0002 \\
\hline & & $(.0040)$ & $(.0040)$ & $(.0038)$ & $(.0038)$ & $(.0023)$ & $(.0022)$ \\
\hline \multirow[t]{2}{*}{ Wage above advertised ${ }^{3}$} & & -.0004 & .0001 & -.0011 & -.0019 & $-.0074 * * *$ & $-.0084 * * *$ \\
\hline & & $(.0039)$ & $(.0039)$ & $(.0039)$ & $(.0042)$ & $(.0023)$ & $(.0023)$ \\
\hline \multirow[t]{2}{*}{ Sex differs from requested } & & $-.0109 * *$ & $-.0105 * *$ & $-.0085^{*}$ & -.0060 & $-.0060 *$ & -.0051 \\
\hline & & $(.0050)$ & $(.0050)$ & $(.0047)$ & $(.0045)$ & $(.0033)$ & $(.0031)$ \\
\hline \multirow[t]{2}{*}{ Number of positions advertised (/100) } & & & & & $.5345^{* *}$ & .3016 & \\
\hline & & & & & $(.2177)$ & $(.2015)$ & \\
\hline \multirow[t]{2}{*}{ Number of applicants (/100) } & & & & & $-.0134 * * *$ & $-.0088 * * *$ & \\
\hline & & & & & $(.0027)$ & $(.0023)$ & \\
\hline Detailed CV controls & No & No & Yes & Yes & Yes & Yes & Yes \\
\hline Occupation Fixed Effects & No & No & No & Yes & Yes & Yes & No \\
\hline Firm Fixed Effects & No & No & No & No & No & Yes & No \\
\hline Ad Fixed Effects & No & No & No & No & No & No & Yes \\
\hline Observations & 237,128 & 237,128 & 232,600 & 232,600 & 232,600 & 232,600 & 232,600 \\
\hline R-squared & .0002 & .0045 & .0050 & .0172 & .0269 & .2710 & .2955 \\
\hline
\end{tabular}

Standard errors in parentheses, clustered by ad. $* * * \mathrm{p}<0.01, * * \mathrm{p}<0.05, * \mathrm{p}<0.1$ 
Notes to Table 3:

1. Age matching variables refer to whether the applicant's age is below, within, or above the requested age range.

2. Experience matching variables refer to whether the applicant's experience is below, $0-2$ years above, or more than 3 years above the requested experience level.

3. Wage matching variables refer to whether the applicant's current wage and the advertised wage are in the same wage bin ( 8 bins are used).

In addition to the covariates shown, columns 2-7 include the following covariates: the job's requested education level (5 categories), requested experience level (quadratic), requested age level (quadratic in midpoint of range), requested gender (male, female, not specified), advertised wage (quadratic in midpoint of bin; 8 bins), and dummies for whether a new graduate is requested, for whether the worker is a new graduate, for whether the worker's new graduate status matches the employer's request, and whether the worker is female. Indicators for missing age and wage information for either the ad or the worker are also included.

Columns 3-7 also include controls for the following worker (CV) characteristics (these characteristics are not mentioned in job ads very often): whether attended technical school, the applicant's Zhicheng rank (6 categories), whether the CV is in English, the number of schools attended, number of job experience spells, number of certifications reported, applicant height (interacted with applicant gender), an indicator for myopia indicator (interacted with applicant gender), and marital status (interacted with applicant gender).

Sample size drops between columns 3 and 4 because height information is missing for 1.9 percent of the cvs. 
Table 4: Effects of Non-Local Hukou (NLH) on Job Offer Probabilities, by Required Education:

Detailed CV controls

Occupation Fixed Effects

Firm Fixed Effects

Ad Fixed Effects

Observations

R-squared
(1)

$\begin{array}{cc}.0358 * * * & .0251 * * * \\ (.0097) & (.0077) \\ .0465 * * * & .0352 * * * \\ (.0134) & (.0118) \\ .0184 * * & .0234 * * * \\ (.0077) & (.0072) \\ -.0115 & -.0087 \\ (.0104) & (.0104) \\ .0079 & .0032 \\ (.0051) & (.0040) \\ -.0032 & .0059 \\ (.0115) & (.0093)\end{array}$

(2)

(3)

$.0240 * * *$
$(.0078)$
$.0339 * * *$
$(.0121)$
$.0214 * * *$
$(.0072)$
-.0083
$(.0104)$
.0024
$(.0040)$
.0053
$(.0088)$
Yes

237,128

.0022

237,128

.0046

$.0212 * * *$
$(.0079)$
$.0351 * * *$
$(.0123)$
$.0164 * *$
$(.0073)$
-.0044
$(.0106)$
.0023
$(.0038)$
.0035
$(.0088)$
Yes
Yes

\section{(4)}

(5)

$.0214 * * *$
$(.0079)$
$.0365 * * *$
$(.0123)$
$.0143 * *$
$(.0072)$
.0020
$(.0104)$
.0042
$(.0038)$
.0050
$(.0087)$
Yes
Yes

232,600

.0173
(6)

$\begin{array}{cc}.0114 * & .0117 * * \\ (.0058) & (.0059) \\ .0262 * * & .0216 * * \\ (.0109) & (.0107) \\ .0225 * * * & .0159 * * * \\ (.0064) & (.0058) \\ -.0194 * * & -.0105 \\ (.0082) & (.0070) \\ .0057 * & .0057 * * \\ (.0029) & (.0029) \\ .0002 & .0025 \\ (.0050) & (.0050) \\ \text { Yes } & \text { Yes } \\ \text { Yes } & \text { Yes } \\ \text { Yes } & \text { No } \\ & \text { Yes } \\ 232,600 & 232,600 \\ .2711 & .2956\end{array}$

Standard errors in parentheses, clustered by ad $* * * \mathrm{p}<0.01, * * \mathrm{p}<0.05, * \mathrm{p}<0.1$

See Table 3 for regression specifications. 
Table 5: Effects of Non-Local Hukou (NLH) on Contact Rate, by the Job's Posted Wage Level:

\begin{tabular}{|c|c|c|c|c|c|c|c|}
\hline & (1) & (2) & (3) & (4) & (5) & (6) & (7) \\
\hline \multicolumn{8}{|l|}{ Posted Wage: } \\
\hline \multirow[t]{2}{*}{ Around 1000 yuan/month } & $.0795 * *$ & $.0846 * *$ & $.0843^{* *}$ & $.0873 * *$ & $.0756^{*}$ & .0264 & -.0090 \\
\hline & $(.0331)$ & $(.0358)$ & $(.0363)$ & $(.0368)$ & $(.0388)$ & $(.0501)$ & $(.0678)$ \\
\hline \multirow[t]{2}{*}{$1000-2000$ yuan/month } & $.0128 * *$ & $.0175^{* * *}$ & $.0154 * *$ & $.0130 * *$ & $.0138 * *$ & $.0139 * * *$ & $.0142 * * *$ \\
\hline & $(.0065)$ & $(.0061)$ & $(.0061)$ & $(.0059)$ & $(.0058)$ & $(.0047)$ & $(.0048)$ \\
\hline \multirow[t]{2}{*}{ 2000-3000 yuan/month } & .0073 & .0038 & .0012 & .0011 & .0047 & .0073 & .0059 \\
\hline & $(.0061)$ & $(.0061)$ & $(.0060)$ & $(.0057)$ & $(.0058)$ & $(.0045)$ & $(.0048)$ \\
\hline \multirow{2}{*}{ 3000-4000 yuan/month } & .0099 & .0009 & -.0007 & -.0038 & -.0094 & -.0097 & .0071 \\
\hline & $(.0149)$ & $(.0150)$ & $(.0150)$ & $(.0147)$ & $(.0142)$ & $(.0100)$ & $(.0078)$ \\
\hline \multirow[t]{2}{*}{ 4000-5000 yuan/month } & $.0525 * *$ & $.0379 *$ & $.0374^{*}$ & .0345 & .0293 & .0326 & .0018 \\
\hline & $(.0255)$ & $(.0223)$ & $(.0224)$ & $(.0215)$ & $(.0208)$ & $(.0201)$ & $(.0165)$ \\
\hline \multirow{2}{*}{ More than 5000 yuan/month } & $.0423 * *$ & .0108 & .0107 & .0071 & .0062 & -.0315 & -.0216 \\
\hline & $(.0196)$ & $(.0337)$ & $(.0339)$ & $(.0351)$ & $(.0332)$ & $(.0276)$ & $(.0275)$ \\
\hline Basic Ad, CV and Match controls & & Yes & Yes & Yes & Yes & Yes & Yes \\
\hline Detailed CV controls & & & Yes & Yes & Yes & Yes & Yes \\
\hline Occupation Fixed Effects & & & & Yes & Yes & Yes & Yes \\
\hline Firm Fixed Effects & & & & & & Yes & No \\
\hline Ad Fixed Effects & & & & & & & Yes \\
\hline Observations & 96,689 & 96,689 & 95,477 & 95,477 & 95,477 & 95,477 & 95,477 \\
\hline R-squared & .0015 & .0053 & .0061 & .0148 & .0232 & .2539 & .2727 \\
\hline
\end{tabular}

Standard errors in parentheses, clustered by ad $* * * \mathrm{p}<0.01, * * \mathrm{p}<0.05, * \mathrm{p}<0.1$

See Table 3 for Regression Specifications. 
Table 6: Effects of Non-Local Hukou (NLH) on Contact Rate, by whether a wage was advertised:

\begin{tabular}{|c|c|c|c|c|c|c|c|}
\hline & (1) & (2) & (3) & (4) & $(5)$ & (6) & $(7)$ \\
\hline Ad posted a wage & $\begin{array}{c}.0144 * * * \\
(.0035)\end{array}$ & $\begin{array}{c}.0137 * * * \\
(.0030)\end{array}$ & $\begin{array}{c}.0127 * * * \\
(.0030)\end{array}$ & $\begin{array}{c}.0114 * * * \\
(.0030)\end{array}$ & $\begin{array}{c}.0130 * * * \\
(.0029)\end{array}$ & $\begin{array}{c}.0070 * * * \\
(.0023)\end{array}$ & $\begin{array}{c}.0067 * * * \\
(.0023)\end{array}$ \\
\hline Ad didn't post a wage & $\begin{array}{c}.0135 * * * \\
(.0040)\end{array}$ & $\begin{array}{l}.0107 * * \\
(.0042)\end{array}$ & $\begin{array}{l}.0095^{* *} \\
(.0042)\end{array}$ & $\begin{array}{l}.0079 * * \\
(.0040)\end{array}$ & $\begin{array}{l}.0097 * * \\
(.0039)\end{array}$ & $\begin{array}{c}.0100 * * * \\
(.0031)\end{array}$ & $\begin{array}{c}.0100 * * * \\
(.0031)\end{array}$ \\
\hline Basic Ad, CV and Match controls & & Yes & Yes & Yes & Yes & Yes & Yes \\
\hline Detailed CV controls & & & Yes & Yes & Yes & Yes & Yes \\
\hline Occupation Fixed Effects & & & & Yes & Yes & Yes & Yes \\
\hline Firm Fixed Effects & & & & & & Yes & No \\
\hline Ad Fixed Effects & & & & & & & Yes \\
\hline Observations & 237,128 & 237,128 & 232,600 & 232,600 & 232,600 & 232,600 & 232,600 \\
\hline R-squared & .0002 & .0045 & .0050 & .0172 & .0269 & .2710 & .2955 \\
\hline$p$-value for posted wage $=$ not posted & .8669 & .5438 & .5265 & .4896 & .5072 & .4355 & .3767 \\
\hline
\end{tabular}

Standard errors in parentheses, clustered by ad $* * * \mathrm{p}<0.01, * * \mathrm{p}<0.05, * \mathrm{p}<0.1$

See Table 3 for Regression Specifications. 
Table 7: Effects of Non-Local Hukou (NLH) on Contact Rate, by Applicants' gender and marital status

\begin{tabular}{|c|c|c|c|c|c|c|c|}
\hline & (1) & (2) & (3) & (4) & (5) & (6) & (7) \\
\hline \multirow[t]{2}{*}{ single*female } & $.0085 * *$ & $.0086^{* *}$ & $.0062 *$ & .0052 & $.0077 * *$ & $.0051 *$ & $.0057 * *$ \\
\hline & $(.0037)$ & $(.0036)$ & $(.0037)$ & $(.0035)$ & $(.0034)$ & $(.0028)$ & $(.0028)$ \\
\hline \multirow[t]{2}{*}{ married*female } & .0045 & .0033 & .0071 & .0041 & .0073 & .0056 & .0068 \\
\hline & $(.0041)$ & $(.0041)$ & $(.0056)$ & $(.0054)$ & $(.0053)$ & $(.0042)$ & $(.0042)$ \\
\hline \multirow[t]{2}{*}{ single*male } & $.0210 * * *$ & $.0204 * * *$ & $.0161 * * *$ & $.0149 * * *$ & $.0148 * * *$ & $.0103 * * *$ & $.0096 * * *$ \\
\hline & $(.0041)$ & $(.0037)$ & $(.0040)$ & $(.0040)$ & $(.0040)$ & $(.0033)$ & $(.0033)$ \\
\hline \multirow[t]{2}{*}{ married*male } & $.0217 * * *$ & $.0164 * * *$ & $.0233 * * *$ & $.0220 * * *$ & $.0229 * * *$ & $.0167 * * *$ & $.0134 * * *$ \\
\hline & $(.0057)$ & $(.0046)$ & $(.0061)$ & $(.0061)$ & $(.0060)$ & $(.0048)$ & $(.0048)$ \\
\hline Basic Ad, CV and Match controls & & Yes & Yes & Yes & Yes & Yes & Yes \\
\hline Detailed CV controls & & & Yes & Yes & Yes & Yes & Yes \\
\hline Occupation Fixed Effects & & & & Yes & Yes & Yes & Yes \\
\hline Firm Fixed Effects & & & & & & Yes & No \\
\hline Ad Fixed Effects & & & & & & & Yes \\
\hline Observations & 237,128 & 237,128 & 232,600 & 232,600 & 232,600 & 232,600 & 232,600 \\
\hline $\mathrm{R}$-squared & .0007 & .0045 & .0050 & .0173 & .0270 & .2710 & .2955 \\
\hline
\end{tabular}

Standard errors in parentheses, clustered by ad $* * * \mathrm{p}<0.01, * * \mathrm{p}<0.05, * \mathrm{p}<0.1$

See Table 3 for Regression Specifications. 
Table 8: Effects of Origin Provinces' GDP on the Probability Employer Contact for Non-Local Hukou (NLH)

\begin{tabular}{|c|c|c|c|c|c|c|c|}
\hline & (1) & (2) & (3) & (4) & $(5)$ & $(6)$ & (7) \\
\hline \multicolumn{8}{|l|}{ A. Full Sample } \\
\hline \multirow[t]{2}{*}{ Non-Local Hukou (NLH) } & $.0123 * * *$ & $.0114 * * *$ & $.0105 * * *$ & $.0094 * * *$ & $.0113 * * *$ & $.0083 * * *$ & $.0082 * * *$ \\
\hline & $(.0028)$ & $(.0026)$ & $(.0025)$ & $(.0024)$ & $(.0024)$ & $(.0019)$ & $(.0019)$ \\
\hline \multirow[t]{2}{*}{ Other than Fujian (Local) Province $(\mathrm{OH})$} & $.0077 * * *$ & $.0063 * * *$ & $.0049 * *$ & .0029 & .0016 & -.0009 & -.0014 \\
\hline & $(.0024)$ & $(.0023)$ & $(.0023)$ & $(.0022)$ & $(.0022)$ & $(.0018)$ & $(.0018)$ \\
\hline \multirow[t]{2}{*}{$\mathrm{OH}^{*}$ Origin Province's per capita GDP } & $-.0044^{*}$ & -.0023 & -.0026 & -.0028 & -.0030 & $-.0034 *$ & -.0031 \\
\hline & $(.0025)$ & $(.0023)$ & $(.0023)$ & $(.0023)$ & $(.0023)$ & $(.0020)$ & $(.0020)$ \\
\hline \multirow[t]{2}{*}{$\mathrm{OH}^{*} \log$ of Railroad Distance (in km) } & $.0051 * *$ & $.0052 * *$ & $.0047 * *$ & .0031 & .0029 & .0017 & .0014 \\
\hline & $(.0024)$ & $(.0023)$ & $(.0023)$ & $(.0023)$ & $(.0023)$ & $(.0019)$ & $(.0018)$ \\
\hline Observations & 237,127 & 237,127 & 232,599 & 232,599 & 232,599 & 232,599 & 232,599 \\
\hline R-squared & .0003 & .0045 & .0050 & .0172 & .0269 & .2710 & .2955 \\
\hline \multicolumn{8}{|c|}{ B. Jobs Requiring High School Education or Less } \\
\hline \multirow[t]{2}{*}{ Non-Local Hukou (NLH) } & $.0229 * * *$ & $.0222 * * *$ & $.0218 * * *$ & $.0186 * * *$ & $.0192 * * *$ & $.0152 * * *$ & $.0147 * * *$ \\
\hline & $(.0052)$ & $(.0050)$ & $(.0050)$ & $(.0046)$ & $(.0045)$ & $(.0038)$ & $(.0038)$ \\
\hline \multirow[t]{2}{*}{ Other than Fujian (Local) Province $(\mathrm{OH})$} & .0056 & .0043 & .0034 & .0024 & .0006 & -.0007 & -.0009 \\
\hline & $(.0047)$ & $(.0045)$ & $(.0044)$ & $(.0042)$ & $(.0043)$ & $(.0037)$ & $(.0036)$ \\
\hline \multirow[t]{2}{*}{$\mathrm{OH}^{*}$ Origin Province's per capita GDP } & $-.0084 *$ & -.0074 & $-.0085^{*}$ & $-.0080^{*}$ & $-.0087 * *$ & -.0052 & -.0045 \\
\hline & $(.0047)$ & $(.0047)$ & $(.0046)$ & $(.0044)$ & $(.0043)$ & $(.0038)$ & $(.0038)$ \\
\hline \multirow[t]{2}{*}{$\mathrm{OH}^{*} \log$ of Railroad Distance (in km) } & .0059 & .0061 & .0059 & .0053 & .0052 & .0030 & .0025 \\
\hline & $(.0039)$ & $(.0039)$ & $(.0040)$ & $(.0039)$ & $(.0039)$ & $(.0032)$ & $(.0032)$ \\
\hline Observations & 74,429 & 74,429 & 73,344 & 73,344 & 73,344 & 73,344 & 73,344 \\
\hline R-squared & .0006 & .0073 & .0079 & .0278 & .0374 & .2664 & .2902 \\
\hline \multicolumn{8}{|c|}{ C. Jobs Requiring Tech School Education or More } \\
\hline \multirow[t]{2}{*}{ Non-Local Hukou (NLH) } & $.0076^{* *}$ & $.0068 * *$ & $.0062 * *$ & $.0054 *$ & $.0075 * * *$ & $.0054 * *$ & $.0057 * * *$ \\
\hline & $(.0033)$ & $(.0030)$ & $(.0029)$ & $(.0028)$ & $(.0028)$ & $(.0022)$ & $(.0022)$ \\
\hline \multirow[t]{2}{*}{ Other than Fujian (Local) Province $(\mathrm{OH})$} & $.0070 * *$ & $.0066^{* *}$ & $.0049 *$ & .0018 & .0009 & -.0014 & -.0019 \\
\hline & $(.0028)$ & $(.0027)$ & $(.0026)$ & $(.0025)$ & $(.0024)$ & $(.0020)$ & $(.0020)$ \\
\hline \multirow[t]{2}{*}{$\mathrm{OH}^{*}$ Origin Province's per capita GDP } & -.0001 & .0001 & -.0003 & -.0003 & -.0004 & -.0027 & -.0023 \\
\hline & $(.0027)$ & $(.0026)$ & $(.0027)$ & $(.0026)$ & $(.0026)$ & $(.0023)$ & $(.0023)$ \\
\hline \multirow[t]{2}{*}{$\mathrm{OH}^{*} \log$ of Railroad Distance (in $\mathrm{km}$ ) } & .0041 & .0044 & .0035 & .0008 & .0007 & .0008 & .0006 \\
\hline & $(.0029)$ & $(.0029)$ & $(.0029)$ & $(.0028)$ & $(.0028)$ & $(.0023)$ & $(.0022)$ \\
\hline Observations & 162,698 & 162,698 & 159,255 & 159,255 & 159,255 & 159,255 & 159,255 \\
\hline R-squared & .0002 & .0026 & .0034 & .0203 & .0320 & .2805 & .2972 \\
\hline
\end{tabular}

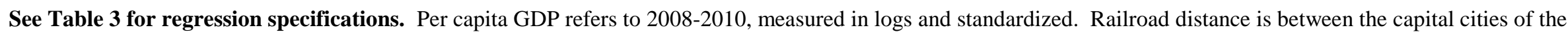
origin province and Fujian (Bodvarsson, Hou and Shen (2014) and is normalized to have a mean of zero for the non-Fujian provinces. 
Figure 1: Mean Callback Rates of NLH Applicants by Origin Province's per capita GDP

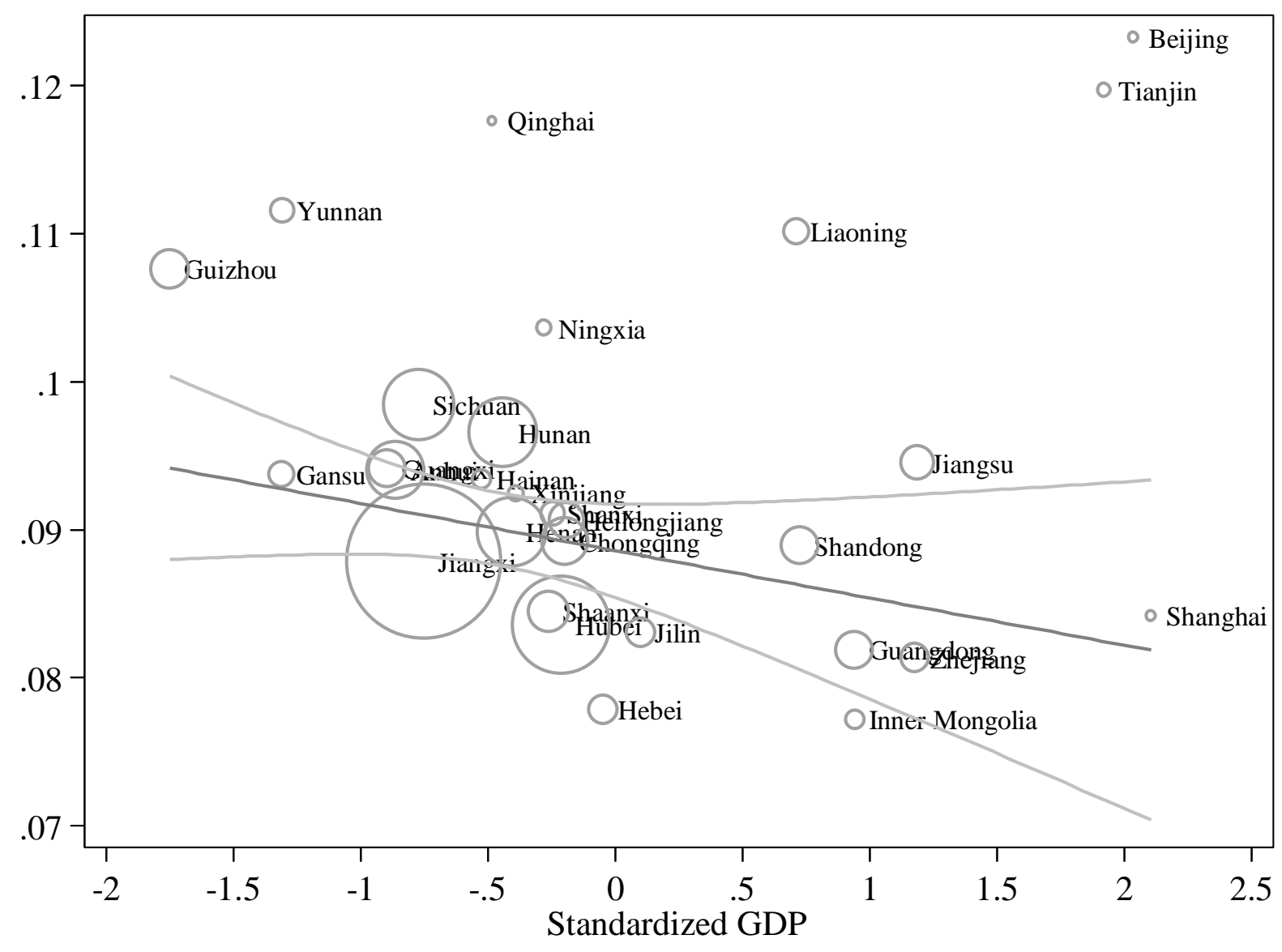

Symbol size is proportional to the number of observations from the source province.

Linear regression line is weighted by number of observations from the province; $95 \%$ confidence band is shown. 